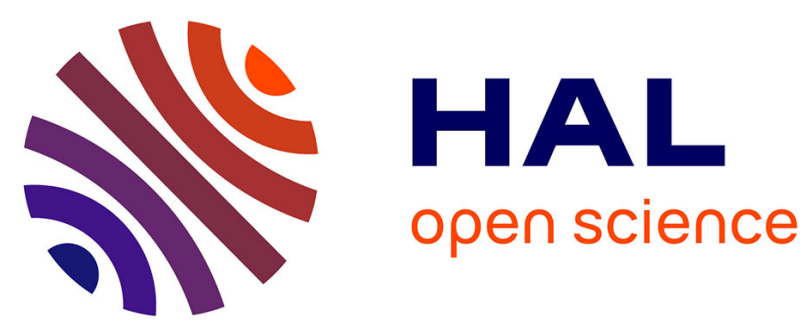

\title{
An ALE-FEM approach to the thermomechanics of solidification processes with application to prediction of pipe shrinkage
}

\author{
Michel Bellet, Olivier Jaouen, Isabelle Poitrault
}

\section{- To cite this version:}

Michel Bellet, Olivier Jaouen, Isabelle Poitrault. An ALE-FEM approach to the thermomechanics of solidification processes with application to prediction of pipe shrinkage. International Journal of Numerical Methods for Heat and Fluid Flow, 2005, 15 (2), pp.120-142. 10.1108/09615530510578410 . hal-00517660

HAL Id: hal-00517660

https://hal-mines-paristech.archives-ouvertes.fr/hal-00517660

Submitted on 11 Mar 2011

HAL is a multi-disciplinary open access archive for the deposit and dissemination of scientific research documents, whether they are published or not. The documents may come from teaching and research institutions in France or abroad, or from public or private research centers.
L'archive ouverte pluridisciplinaire HAL, est destinée au dépôt et à la diffusion de documents scientifiques de niveau recherche, publiés ou non, émanant des établissements d'enseignement et de recherche français ou étrangers, des laboratoires publics ou privés. 
Int. J. Num. Meth. Heat Fluid Flow 15 (2005) 120-142

\author{
An ALE-FEM Approach to the \\ Thermomechanics of Solidification Processes \\ with Application to the Prediction of Pipe Shrinkage
}

Michel Bellet ${ }^{1}$, Olivier Jaouen ${ }^{2}$, Isabelle Poitrault ${ }^{3}$

${ }^{1}$ Ecole des Mines de Paris, Centre de Mise en Forme des Matériaux (CEMEF), UMR CNRS 7635, BP 207, F-06904 Sophia Antipolis, France. E-mail: michel.bellet@ensmp.fr

${ }^{2}$ Transvalor S.A., Parc de Haute Technologie, Sophia Antipolis, 694 avenue du Dr. Maurice Donat, F-06255 Mougins Cedex, France

${ }^{3}$ Industeel, Centre de Recherche des Matériaux, 56 rue Clemenceau, BP 56, F-71202 Le Creusot, France 


\author{
An ALE-FEM Approach to the \\ Thermomechanics of Solidification Processes \\ with Application to the Prediction of Pipe Shrinkage
}

\begin{abstract}
The present paper addresses the computer modelling of pipe formation in castings. As a preliminary, a brief review of the current state-of-the-art in pipe shrinkage computation is presented: most of existing methods are based on thermal considerations only. In the current paper, it is demonstrated that this typical evolution of the free surface, originated by shrinkage at solidification front and compensating feeding liquid flow, can be effectively approached by a thermomechanical analysis in the frame of the finite element method (FEM) and the arbitrary Lagrangian-Eulerian (ALE) formulation. In a first part, the constitutive equations that have to be considered in thermomechanical computations are presented. This point is central because the cast alloy is simultaneously present in liquid, mushy and solid state. Then the main lines of the mechanical finite element resolution are given, insisting on the fact that it permits the concurrent computation of stresses and strains in solidified areas and of liquid flow in still liquid or mushy zones. A detailed presentation of the Eulerian-Lagrangian formulation follows, explaining the connection between the Lagrangian and the quasi Eulerian zones, and the treatment of free surfaces. Finally, an example of application to an industrial casting is given.
\end{abstract}

Keywords: numerical simulation, finite elements, solidification, casting, thermomechanics, shrinkage, pipe formation, ALE formulation. 


\section{Introduction}

The complexity of phenomena encountered in casting processes makes numerical modelling a very useful tool to predict the final state of cast products and optimize the process. Numerical developments have long been focused on thermal and microstructural aspects, which are of primary importance in casting analysis. However, during the last ten years, there has been a growing interest in the modelling of the mechanical aspects of solidification processes (Cross and Campbell, 1995; Thomas and Beckermann, 1998). The objectives are then to evaluate thermal stresses and strains during solidification, in order to examine how the latter can significantly affect heat exchanges at interfaces, provide key elements for crack prediction and evaluate the residual stresses and deformations of cast products.

In the present paper, we will focus on the formation of the pipe defect, or open shrinkage, which occurs in the risers attached to cast parts or ingots. This defect results from the contraction of the alloy during solidification. The loss of volume, which is localized at the solidification front, is compensated by a fluid flow coming from the risers, through the liquid and mushy zones. This generates in turn a change in the metal level in the risers. This level decrease, associated with the progress of the solidification, generates the collapse of the metal free surface, creating the so-called pipe defect. The prediction of this defect is of major importance especially in the case of heavy ingots or large parts cast in small series. For such parts, the risers represent an important fraction of the total amount of liquid metal and the reduction of their size can lead to considerable savings.

The prediction of this defect has long been tackled using the Niyama criterion (Niyama et al., 1982), although this indicator had been developed essentially to predict internal microporosities, on the basis of thermal variables, namely the cooling rate and the temperature gradient. This approach is still in use in a lot of simulation packages.

An alternative approach has been proposed by Roch et al. in an article dedicated to the twodimensional analysis of heat transfer and fluid flow in the solidification of heavy steel ingots (Roch et al., 1991). The authors simply remark that knowing the amount of solid that is formed at each time step, it is easy to deduce the free volume to be compensated by the feeding flow. Thus, this incremental free volume is used to deduce the decrease of the liquid metal surface. To take into account the incremental solidification that occurs in the riser, the intercept of the new metal level with the solidus isotherm is calculated: the free volume is delimited by the previous level, the new level, and the solidus isotherm. Hence, the pipe formation analysis is not directly incorporated in the governing equations for fluid flow but rather it is implemented after the completion of each time step. In other words, the feeding is considered as perfect in this case: the entire shrinkage volume is assigned to the pipe formation and the liquid feeding cannot be interrupted by an excessive pressure drop arising from a too low permeability of the mushy zone. An additional drawback of this method appears when considering the possible presence of several risers. How to assign the global incremental free volume to the different risers? This would need specific additional rules to be calculated, possibly coming from the classical dimensioning of risers. 
Another approach has been initiated by Barkhudarov and co-workers (Barkhudarov et al., 1993). Like Roch et al., they perform a two-dimensional coupled resolution of heat transfer and fluid flow in the solidifying part. Then, adding a volume sink term in the fluid flow equation, representing the local rate of volumetric shrinkage, and using the VOF (volume of fluid ) algorithm for free surface tracking, predictions of free surface evolution and pipe formation can be obtained. However, the equations governing the flow in the mushy zone are expressed in a rough way, and the approach is affected by the usual numerical diffusion of such front tracking algorithms. This idea has been taken up by Naterer (Naterer, 1997) and Ehlen et al. (Ehlen et al.,2000) including this time Darcy terms to model the liquid flow in the mushy zone. Naterer also proposes a specific treatment of the updating of surface nodes to model the free surface evolution. A remark that can be done regarding all the previous analyses is that some additional contributions to volume changes are not taken into account: first, the thermal contraction of the metal both in liquid and in solid state, all along its cooling down, and, second, the possible opening of air gaps between part and mold.

In the present paper, we would like to show that the finite element arbitrary LagrangianEulerian (ALE) approach can offer a unified framework in order to take into account the major contributions to pipe formation. As a matter of fact, the Lagrangian character permits a precise description of the evolution of the boundary of the computational domain. This is essential to treat air gap opening for instance. At the same time, a quasi Eulerian formulation allows the computation of thermal convection in liquid pools and the feeding flow originated by solidification shrinkage. Finally, we will show that regarding the free surface evolution - and consequently the prediction of pipe formation - the ALE formulation can provide an efficient solution.

The present work is a contribution to the development of the THERCAST ${ }^{\circledR}$ software at Cemef laboratory and Transvalor. This finite element code has been first developed as a threedimensional thermomechanical solver for solidification problems (Bellet et al., 1996), using hexahedral elements. Then tetrahedral linear finite elements have been implemented, using a mixed velocity-pressure formulation, as well as automatic meshing and remeshing capacities (Ménaï and Bellet, 1995). More recently, a clear distinction between solid-like and liquid-like constitutive equations for the solidifying alloys has been shown mandatory to treat in a simultaneous manner the deformation of the solidified regions of a casting and the liquid flow due to thermal convection. This has given rise to a first implementation of the ALE formulation (Jaouen, 1998; Bellet and Jaouen, 1999) in the context of a multidomain analysis, including mold deformation (Jaouen, 1998).

In the present paper, we will address the numerical issues that are directly connected to the pipe formation prediction. Hence, we invite the interested reader to consult the references quoted in the previous paragraph to get more information about the heat transfer resolution or the basics of the mechanical formulation as well as the thermomechanical coupling. In section 1, we will present the two types of constitutive equations (liquid-like and solid-like) that are used simultaneously in the mechanical resolution. In section 2, the finite element discretization of the mechanical equations will be described. Section 3 will be devoted to the presentation of the ALE formulation. 
Section 4 will present an application to an industrial casting with comparison to experimental measurements of the shape of the pipe defect.

\section{Constitutive equations for metallic alloys in solidification conditions}

The earlier works dealing with the modelling of thermomechanical phenomena in casting processes (stress-strain computations) generally have been based on elastic-viscoplastic constitutive equations for the material behavior (Weiner and Boley, 1963; Smelser and Richmond, 1988; Fjaer and Mo, 1990; Wiese and Dantzig, 1990; ; Inoue and Ju, 1992; Moitra et al., 1992; Celentano et al., 1993; Zhang et al., 1994; Ménaï and Bellet, 1995; Bellet et al., 1996). The material parameters are then temperature dependant in order to model the evolution of the material behavior over a very large temperature interval, including the liquid-solid phase change. However, it has become clear that such a formulation fails to predict accurately those phenomena (Jaouen, 1998). For instance, several drawbacks of this approach can be mentioned.

First, the change of specific volume associated with the liquid-solid phase change cannot be modeled adequately using a single elastic-viscoplastic constitutive equation because it causes artificial elastic stresses. A direct consequence is the poor quality of the prediction of the amount of volumetric shrinkage.

Second, regarding the modelling of the liquid phase, this approach is unable to provide a simple and acceptable representation of liquid or mushy states. The use of such a single model supposes the fluid to be at rest. This excludes the modelling of fluid motion associated with thermal or solutal convection, and so the relevant computation of the distribution of temperature and alloying elements in the liquid pool.

To overcome those difficulties, it is suggested here to make a clear distinction between the constitutive equations used for the liquid or mushy state, and for the solid state of the alloys. In the model proposed here, the liquid or mushy state is modeled using a pure thermo-viscoplastic law, without any elastic contribution. Depending on the temperature (or the solid fraction), the model is either purely Newtonian (pure liquid state) or non linear viscoplastic (mushy state). Below a critical temperature $T_{C}$ (for instance the "coherency" temperature or the solidus temperature), the alloy behavior is modeled by a thermo-elastic-viscoplastic constitutive law, which is more representative of solid-like behavior. We first present the two kind of models in the next two paragraphs. In section 2, it will be shown how those two models can be used simultaneously in a single finite element resolution.

\section{$\underline{1.1 \text { Liquid-like constitutive equations }}$}

A pure thermo-viscoplastic model is used. In this case, the compressibility is only due to the thermal contribution (no elasticity). The equations of the constitutive model can be written as follows:

$$
\dot{\boldsymbol{\varepsilon}}=\dot{\boldsymbol{\varepsilon}}^{v p}+\dot{\boldsymbol{\varepsilon}}^{t h}
$$




$$
\begin{aligned}
& \dot{\boldsymbol{\varepsilon}}^{v p}=\frac{1}{2 K}\left(\sqrt{3} \dot{\varepsilon}_{e q}\right)^{1-m} \boldsymbol{s} \\
& \dot{\boldsymbol{\varepsilon}}^{t h}=\left(\alpha \dot{T}+\frac{1}{3} \dot{g}_{s} \Delta \varepsilon^{t r}\right) \boldsymbol{I}
\end{aligned}
$$

in which the strain rate tensor $\dot{\boldsymbol{\varepsilon}}$ is split into a viscoplastic, and a thermal part (1). The latter includes thermal expansion and shrinkage due to the liquid-solid phase change (3), $\dot{T}$ being the temperature rate, $\alpha$ the thermal linear expansion coefficient, $\dot{g}_{s}$ the rate of the volumic solid fraction, $\Delta \varepsilon^{t r}$ the relative volume change due to the total liquid-solid transition and $\boldsymbol{I}$ the identity tensor. Equation (2) is the classical constitutive equation of a generalized non Newtonian fluid. It relates the viscoplastic strain rate to the stress deviator $s$, which is in turn defined by:

$$
\boldsymbol{s}=\boldsymbol{\sigma}+p \boldsymbol{I}
$$

in which $\sigma$ is the Cauchy stress tensor and $p$ the associated hydrostatic pressure. In relation (2) $K$ is the so-called consistency of the material and $m$ is the strain-rate sensitivity coefficient, while $\dot{\varepsilon}_{e q}$ is the von Mises equivalent strain-rate, defined by:

$$
\dot{\varepsilon}_{e q}=\sqrt{\frac{2}{3} \dot{\varepsilon}_{i j}^{v p} \dot{\varepsilon}_{i j}^{v p}}
$$

The limit case of the Newtonian behavior (liquid state) is obtained for $m=1$. In this case, $K$ is simply the dynamic viscosity of the liquid.

\section{$\underline{1.2 \text { Solid-like constitutive equations }}$}

A thermo-elastic-viscoplastic model is used to represent the solidifying material behavior. It is described by the following equations:

$$
\begin{aligned}
& \dot{\boldsymbol{\varepsilon}}=\dot{\boldsymbol{\varepsilon}}^{e l}+\dot{\boldsymbol{\varepsilon}}^{v p}+\dot{\boldsymbol{\varepsilon}}^{t h} \\
& \dot{\boldsymbol{\varepsilon}}^{e l}=\left(\boldsymbol{D}^{e l}\right)^{-1} \dot{\boldsymbol{\sigma}}=\frac{1+v}{E} \dot{\boldsymbol{\sigma}}-\frac{\boldsymbol{v}}{E} \operatorname{tr}(\dot{\boldsymbol{\sigma}}) \boldsymbol{I} \\
& \dot{\boldsymbol{\varepsilon}}^{v p}=\frac{\partial Q}{\partial \boldsymbol{\sigma}}=\frac{\sqrt{3}}{2 \sigma_{e q}}\left(\frac{\sigma_{e q}-\sigma_{00}-H \varepsilon_{e q}^{n}}{K \sqrt{3}}\right)^{\frac{1}{m}} \boldsymbol{s} \\
& \dot{\boldsymbol{\varepsilon}}^{t h}=\left(\alpha \dot{T}+\frac{1}{3} \dot{g}_{s} \Delta \varepsilon^{t r}\right) \boldsymbol{I}
\end{aligned}
$$

The strain rate tensor $\dot{\boldsymbol{\varepsilon}}$ is split in an elastic, a viscoplastic, and a thermal part (6). As in the fluid-like model, the latter includes thermal expansion and shrinkage due to the liquid-solid phase change (relation (9) or (3)). Equation (7) yields the hypoelastic Hooke's law, where $E$ is Young's 
modulus, $v$ the Poisson's coefficient, $\boldsymbol{D}^{e l}$ the elasticity tensor and $\dot{\boldsymbol{\sigma}}$ a time derivative of the stress tensor. Equation (8) gives the relation between the viscoplastic strain rate and the stress deviator $\boldsymbol{s}$, in which $\sigma_{e q}$ is the von Mises equivalent stress defined by:

$$
\sigma_{e q}=\sqrt{\frac{3}{2} s_{i j} s_{i j}}
$$

In (8) $\sigma_{0}=\sigma_{00}+H \varepsilon_{e q}{ }^{n}$ denotes the static yield stress below which no viscoplastic deformation occurs (the expression between brackets is reduced to zero when negative).

In THERCAST ${ }^{\circledR}$ software, all material parameters of constitutive equations can be defined point-wise as a function of temperature.

\section{Constitutive equations : discussion}

The critical temperature $T_{C}$ separating the two constitutive models can be chosen arbitrarily. If we refer to previous works dedicated to the rheological characterization of metallic slurries (Vicente-Hernandez, 1994; Decultieux et al., 1997) it seems that the limit temperature could be taken equal to the "coherency" temperature, which is defined as the temperature below which the semi-solid medium can support stresses, due to the setting up of a continuous solid skeleton. In this case, the transition temperature between the two types of constitutive models is located within the solidification interval. This means that elastic effects begin to be noticeable in the mushy state, at high solid fraction (typically $g_{s}>0.75$ ).

An alternative could be to take a transition temperature $T_{C}$ lower than the coherency temperature, possibly lower than or equal to the solidus (or eutectic) temperature. If lower, this means that the elastic effects are considered negligible at high temperature in solid state. This is a frequent approximation in hot metal forming analysis.

It can be concluded from those considerations that there is still a great need for experimental rheological work. However, in the authors'opinion, it is really necessary to separate clearly liquidlike and solid-like models in thermomechanical numerical simulations.

It is also worth noting that in the present approach the mushy zone is considered as a single phase continuous medium. In other words, we don't distinguish the velocity of the liquid phase from the velocity of the solid phase. In the context of stress-strain prediction, this approximation seems admissible since the mushy zone probably does not play a prominent role in stress-strain development. But this is clearly a simplification for fluid feeding. Actually the present extension of this approach to the prediction of pipe formation relies on the same physical assumption as used by Roch et al. for instance (Roch et al., 1991): the feeding is considered as perfect, the segregation between liquid flow and solid deformation in the mushy zone is not taken into account. We will see that this remark does not remove anything with the merits of the present ALE formulation. However, in a near future, the implementation of Darcy terms in the momentum equation could be a significant improvement. Finally, to finish with this discussion about constitutive equations, notice that a correct description of the mechanics of the mushy zone would require a real two-phase 
approach, such as the one suggested in (Nguyen et al., 1994) for instance, which consists of the coupling between the deformation of a compressible viscoplastic solid skeleton and the liquid flow obeying the Darcy law. As far as we know, such a comprehensive approach yet has not been applied in the non isothermal context of solidification.

\section{Mechanical equilibrium equations}

At any time, in any domain (the solidifying part or the mold components) the mechanical equilibrium is governed by the momentum equation:

$$
\nabla . \boldsymbol{\sigma}+\rho \boldsymbol{g}-\rho \boldsymbol{\gamma}=\nabla . \boldsymbol{s}-\nabla p+\rho \boldsymbol{g}-\rho \boldsymbol{\gamma}=0
$$

where $\boldsymbol{g}$ denotes the gravity vector and $\boldsymbol{\gamma}$ the acceleration vector. Gravity and inertia can be neglected in the mold components. The acceleration is in fact noticeable only in the liquid pools, when they are affected by fluid convection.

\subsection{Mechanical boundary conditions}

The part boundary $\partial \Omega_{1}$ can be divided into two main regions (the presentation is given here assuming a rigid mold. For the extension of contact boundary conditions to the interaction with deformable mold components, see (Jaouen, 1998)):

- $\partial \Omega_{1 / \text { mold }}$ consists of the boundary regions $\partial \Omega_{1 / j}$ of the part facing the mold components (domains $\Omega_{j}, j \geq 2$ ). The unilateral contact condition is applied to these surfaces:

$$
\left\{\begin{array}{l}
\sigma \boldsymbol{n} . \boldsymbol{n} \leq 0 \\
\delta \geq 0 \\
(\sigma \quad \boldsymbol{n} . \boldsymbol{n}) \delta=0
\end{array}\right.
$$

where $\delta$ is the local interface gap width (positive when air gap exists effectively) and $\boldsymbol{n}$ is the local outward unit normal to the part. The fulfilment of (12) is obtained by means of a penalty condition, which consists in applying a normal stress vector proportional to the normal velocity difference via a penalty constant $\chi_{p}$ (the brackets in the following expression denote the positive part):

$$
\boldsymbol{T}=\boldsymbol{\sigma n}=-\chi_{p}\left\langle\left(\boldsymbol{v}-\boldsymbol{v}_{\text {mold }}\right) . \boldsymbol{n}\right\rangle \boldsymbol{n}
$$

The possible tangential friction effects between part and mold are taken into account by a Coulomb friction model. In this case, the previous stress vector has a tangential component, $\boldsymbol{T}_{\tau}$, given by:

$$
\boldsymbol{T}_{\tau}=-\mu_{f}\left|\sigma_{n}\right| \frac{1}{\left\|\boldsymbol{v}-\boldsymbol{v}_{\text {mold }}\right\|}\left(\boldsymbol{v}-\boldsymbol{v}_{\text {mold }}\right)
$$

where $\sigma_{n}$ is the normal stress, or contact pressure, and $\mu_{f}$ the friction coefficient.

- $\partial \Omega_{1 / \text { press }}$ consists of the regions of $\partial \Omega_{1}$ not facing the mold, i.e. where an external fluid pressure $P_{\text {ext }}(t)$ is prescribed. This pressure can be either the atmospheric pressure, on so-called free 
surfaces, or a prescribed pressure due to the process itself. Consequently, locally, the external stress vector reduces to an applied normal stress vector on $\partial \Omega_{1 / \text { press }}$ :

$$
\boldsymbol{T}=\boldsymbol{\sigma n}=-P_{\text {ext }}(t) \boldsymbol{n}
$$

\subsection{Weak form of mechanical equations}

The primitive variables are velocity and pressure. The problem to be solved is then composed of two equations. The first one is the weak form of the momentum equation, also known as the principle of virtual power. Since $p$ is kept as a primitive variable, only the deviatoric part of constitutive equations is accounted for and has to be solved locally in order to determine the deviatoric stress tensor $\boldsymbol{s}$. Therefore the second equation consists of a weak form of the volumetric part of the constitutive equations. It expresses the incompressibility of the plastic deformation and will govern the pressure evolution. This leads to:

$$
\left\{\begin{array}{l}
\forall \boldsymbol{v}^{*} \int_{\Omega} \boldsymbol{s}: \boldsymbol{\varepsilon}^{*} d V-\int_{\Omega} p \nabla \cdot \boldsymbol{v}^{*} d V-\int_{\partial \Omega} \boldsymbol{T} \cdot \boldsymbol{v}^{*} d S-\int_{\Omega} \rho \boldsymbol{g} \cdot \boldsymbol{v}^{*} d V+\int_{\Omega} \rho \boldsymbol{y} \cdot \boldsymbol{v}^{*} d V=0 \\
\forall p^{*} \quad \int_{\Omega} p^{*} \operatorname{tr} \boldsymbol{\varepsilon}^{v p} d V=0
\end{array}\right.
$$

The pressure variable appears as a Lagrange multiplier of the plastic incompressibility constraint. The form of the term integrated in the second equation will change according to the local state of the alloy (i.e. according to the local temperature). In case of a solid-like constitutive equation (elastic-viscoplastic behavior), it will be:

$$
\operatorname{tr} \dot{\varepsilon}^{v p}=\operatorname{tr} \dot{\varepsilon}-\operatorname{tr} \dot{\varepsilon}^{e l}-\operatorname{tr} \dot{\varepsilon}^{t h}=\nabla \cdot v+\frac{3(1-2 v)}{E} \dot{p}-3 \alpha \dot{T}-\dot{g}_{s} \Delta \varepsilon^{t r}
$$

whereas in case of a liquid-like constitutive equation (pure viscoplastic behavior), the elastic contribution vanishes, yielding:

$$
\operatorname{tr} \dot{\varepsilon}^{v p}=\operatorname{tr} \dot{\varepsilon}-\operatorname{tr} \dot{\varepsilon}^{t h}=\nabla \cdot \boldsymbol{v}-3 \alpha \dot{T}-\dot{g}_{s} \Delta \varepsilon^{t r}
$$

Accordingly, the stress deviator $\boldsymbol{s}$ in (16a) will result either from an elastic-viscoplastic constitutive equation, or from a viscoplastic or Newtonian law.

\subsection{Time discretization}

Given the configuration occupied by the cast part at time $t$, the equations to be solved for ( $v$, $p)^{t}$, velocity and pressure field at time $t$, can be expressed in the following way (for the sake of clarity, we take the case of a thermo-elastic-viscoplastic behavior in the second equation).

$$
\begin{cases}\forall \boldsymbol{v}^{*} & \int_{\Omega^{t}} \boldsymbol{s}\left(\boldsymbol{v}^{t}\right): \dot{\boldsymbol{\varepsilon}}^{*} d V-\int_{\Omega^{t}} p^{t} \nabla \cdot \boldsymbol{v}^{*} d V-\int_{\partial \Omega^{t}} \boldsymbol{T}^{t} \cdot \boldsymbol{v}^{*} d S-\int_{\Omega^{t}} \rho \boldsymbol{g} \cdot \boldsymbol{v}^{*} d V+\int_{\Omega^{t}} \rho \frac{\boldsymbol{v}^{t}-\boldsymbol{v}^{t-\Delta t}}{\Delta t} \cdot \boldsymbol{v}^{*} d V=0 \\ \forall p^{*} & \int_{\Omega^{t}} p^{*}\left(\nabla \cdot \boldsymbol{v}^{t}+\frac{3(1-2 v)}{E} \frac{p^{t}-p^{t-\Delta t}}{\Delta t}-3 \alpha \dot{T}+\dot{g}_{S} \Delta \varepsilon^{t r}\right) d V=0\end{cases}
$$


In this equation, $\dot{T}$ and $\dot{g}_{s}$ are provided by the thermal resolution. The time derivatives of pressure and velocity are approached by implicit Euler backward finite difference schemes:

$$
\dot{p}^{t}=\frac{1}{\Delta t}\left(p^{t}-p^{t-\Delta t}\right) \quad \gamma^{t}=\frac{1}{\Delta t}\left(v^{t}-v^{t-\Delta t}\right)
$$

After resolution, the configuration updating is defined by:

$$
\boldsymbol{x}^{t+\Delta t}=\boldsymbol{x}^{t}+\Delta t \boldsymbol{v}^{t}+\frac{\Delta t^{2}}{2} \boldsymbol{\gamma}^{t}
$$

In the context of solidification, the material velocities and their time derivative remain rather low. Therefore the second order acceleration terms may be neglected.

\subsection{Finite element discretization and resolution}

The finite element mesh is composed of linear tetrahedra. The $\mathrm{P} 1+/ \mathrm{P} 1$ element is used (Arnold et al., 1984; Fortin and Fortin, 1985). The velocity field is linear continuous, including additional degrees of freedom at the center of the element (bubble formulation), and the pressure field is linear continuous (fig. 1). Inside each finite element the discretized velocity and pressure field are expressed as:

$$
\boldsymbol{v}_{h}=\boldsymbol{v}_{h}^{L}+\boldsymbol{b}_{h}=\sum_{n=1}^{4} N_{n} \boldsymbol{V}^{n}+N^{(b)} \boldsymbol{B} \quad p_{h}=\sum_{n=1}^{4} N_{n} P^{n}
$$

The value of the "bubble" interpolation function $N^{(b)}$ is 1 at the tetrahedron center and 0 at its boundary. It is defined separately on each of the four sub-tetrahedra, so that the velocity field is linear on each sub-tetrahedron. The central additional velocity degrees of freedom $\boldsymbol{B}$ permit a better control of the incompressibility constraint. This so-called "mini-element" satisfies the BrezziBabuska condition. Since any virtual velocity field $\boldsymbol{v}_{h}$ can be decomposed by (22), the equilibrium equation is projected onto the $\boldsymbol{v}^{L}$ - or P1 - space and onto the $\boldsymbol{b}$ - or "bubble" - space. Without entering into mathematical details (see (Jaouen, 1998; Bellet and Jaouen, 1999)), such a formulation leads to the elimination of the bubble degrees of freedom (which belong to a unique tetrahedral element) during the finite element assembly process. This leads to the resolution of the following non linear equation:

$$
\boldsymbol{R}(\boldsymbol{V}, \boldsymbol{P})=0
$$

the unknowns of which are the vector $\boldsymbol{V}$ of nodal velocities, and the vector $\boldsymbol{P}$ of nodal pressures. This set of equations is solved by a Newton-Raphson method. At each Newton-Raphson iteration, the resolution of the set of linearized equations for $(\boldsymbol{V}, \boldsymbol{P})$ is performed by an iterative solver with block diagonal preconditioning.

\section{$\underline{2.5 \text { Simultaneous treatment of solid and liquid regions }}$}


Such a mini-element formulation provides a perfect compatibility between the treatment of an elastic-viscoplastic medium and a pure viscoplastic or Newtonian medium. Therefore, it allows to treat simultaneously the solidified zones and the liquid or mushy pools of a casting. The unified form of the mechanical equations can be written in the following way:

$$
\left\{\begin{array}{l}
\forall \boldsymbol{v}^{*} \quad \int_{\Omega}\left\{\begin{array}{l}
\boldsymbol{s}^{e v p} \\
\boldsymbol{s}^{v p}: \boldsymbol{\varepsilon}^{*} d V-\int_{\Omega} p \nabla \cdot \boldsymbol{v}^{*} d V-\int_{\partial \Omega} \boldsymbol{T} \cdot \boldsymbol{v}^{*} d S-\int_{\Omega} \rho \boldsymbol{g} \cdot \boldsymbol{v}^{*} d V+\int_{\Omega} \rho \boldsymbol{\gamma} \cdot \boldsymbol{v}^{*} d V=0 \\
\forall p^{*} \int_{\Omega} p^{*}\left(\nabla \cdot \boldsymbol{v}+\left\{\begin{array}{l}
3 \dot{p}(1-2 v) / E \\
0
\end{array}-3 \alpha \dot{T}-\dot{g}_{s} \Delta \varepsilon^{t r}\right) d V=0\right.
\end{array}\right.
\end{array}\right.
$$

The braces in both equations allow the distinction between the two constitutive models. This choice is done when assembling each finite element, depending on the temperature at center. If the temperature exceeds the critical temperature $T_{C}$, then the whole element is considered viscoplastic (lower line in braces), otherwise it is elastic-viscoplastic (upper line in braces).

\section{ALE formulation in the context of solidification}

During the cooling down of a cast part, the liquid pools can be affected by convection caused by the gradients of the specific mass. Convection can be initiated at high Rayleigh numbers, i.e. when the cast parts are large enough. The specific mass gradients can be caused by gradients of temperature and alloy elements concentration. However, only the thermal convection is considered in the present work.

When considering a constant specific mass $\rho$ in (24), this phenomenon is neglected and liquid pools remain more or less static in the computation. This approximation is acceptable in the case of small parts or for larger ones when liquid convection is neglected in a first approach (the temperature homogenization associated with liquid convection is not captured by the simulation). In this case, the fluid motion is originated by the alloy volumetric contraction during phase change and cooling.

When the local value $\rho(T)$ is used in (24), thermal convection is accounted for. In this case, and provided that the Rayleigh number be high enough, the velocity in the liquid regions are significantly higher than in the solid regions.

In both cases, and especially in the second one, the fluid motion cannot be handled with a classical updated Lagrangian scheme, since it would lead to mesh degeneracy in the liquid pools. At the same time, a purely Eulerian scheme is not satisfying, since it cannot provide enough precision for the evolution of the free surfaces of the mesh: the location of the physical boundary of the part by a front tracking algorithm is irrelevant when dealing with air gap opening for instance. Therefore, a specific arbitrary Lagrangian-Eulerian scheme has been developed and is presented hereunder. 
The basic principle of the ALE method is to separate clearly the mesh velocity field $\boldsymbol{v}_{m s h}$ from the material velocity field $\boldsymbol{v}_{\text {mat }}$ (previously denoted $\boldsymbol{v}$ and coming from the resolution of (23)). Hence the ALE method is between the Lagrangian method $\left(\boldsymbol{v}_{m s h}=\boldsymbol{v}_{m a t}\right)$ and the Eulerian one $\left(\boldsymbol{v}_{m s h}=\right.$ $0)$. There are two main problems to be solved: the computation of the mesh velocity field and the consideration of the velocity difference $\boldsymbol{v}_{m a t}-\boldsymbol{v}_{m s h}$ in the energy and momentum equations (Chenot and Bellet, 1995).

\section{$\underline{3.1 \text { Computation of mesh velocity }}$}

The computation of $\boldsymbol{v}_{m s h}$ consists in regularizing the position of nodes in order to minimize the deformation of the elements of the mesh. Knowing the time step $\Delta t$, the mesh velocity is defined by the relation

$$
\boldsymbol{x}^{t+\Delta t}=\boldsymbol{x}^{t}+\Delta t \boldsymbol{v}_{m s h}
$$

in which $\boldsymbol{x}^{t+\Delta t}$ are the new locations of nodes. These new positions are determined by an iterative procedure which aims at positioning each node at the center of gravity of the set of its neighbors. This is done under the constraint of conservation of material flux through the domain surface:

$$
\boldsymbol{v}_{\text {msh }} \cdot \boldsymbol{n}=\boldsymbol{v}_{\text {mat }} . \boldsymbol{n}
$$

where $\boldsymbol{n}$ is the outward unit normal. This constraint is enforced by a local penalty technique. In order to ensure that equation (26) correctly expresses material flux conservation, we use in this relation the so-called consistent normal vectors defined at surface nodes. Those vectors are such that any tangential nodal velocity (i.e. a velocity which is orthogonal to the consistent normal vector) provides a null contribution to the flux through the discretized surface. As demonstrated in (Bellet, 2001), in the case of linear elements, the consistent normal vector at each surface node $m$ is defined by the average of the normals of the surrounding facets weighted by their surface:

$$
\boldsymbol{n}^{m}=\frac{1}{\left\|\sum_{f \in \tau(m)} S^{f} \boldsymbol{n}^{f}\right\|} \sum_{f \in \tau(m)} S^{f} \boldsymbol{n}^{f}
$$

where $\tau(m)$ denotes the set of triangular facets $f$ the surface node $m$ belongs to, $S^{f}$ being the area of each facet.

In three dimensions, the difficulty of the procedure lies essentially in the treatment of nodes which are in the vicinity of sharp edges and corners of molds and/or which belong to symmetry planes. In this case, the local penalty method can be applied to enforce (26) for several normal vectors.

\section{$\underline{3.2 \text { Treatment of advection terms }}$}

Knowing the mesh velocity, it is now necessary to proceed to the updating of nodal fields, for instance the temperature $T$. This is done by writing for each node: 


$$
T^{t+\Delta t}=T^{t}+\frac{d_{g} T}{d t} \Delta t
$$

where the time derivative of $T$ with respect to the grid can be expressed as follows:

$$
\frac{d_{g} T}{d t}=\frac{d T}{d t}-\left(v_{m a t}-v_{m s h}\right) \cdot \nabla T
$$

Once the heat transfer problem has been solved on the time increment, the total (material) time derivative of the temperature is known at each node. After computation of $\boldsymbol{v}_{m a t}$ and $\boldsymbol{v}_{m s h}$, the updating of the temperature field can be obtained by writing (28-29) at each node and only requires the nodal temperature gradient. Using an upwind technique, this nodal gradient is computed in the upstream element, according to the advection velocity $\boldsymbol{v}_{m a t}-\boldsymbol{v}_{m s h}$ (fig. 2).

In order to express the acceleration terms in the momentum equation, a transport of the material velocity field is necessary. In (19), the velocity $\boldsymbol{v}^{t-\Delta t}$ is the material velocity of the particle at the previous time level $\boldsymbol{v}_{\text {mat }}^{t-\Delta t}$. Hence, after configuration updating, this requires a pure transport of the velocity field. This is achieved by a similar scheme as (28-29), but in which the material derivative is taken equal to zero:

$$
\boldsymbol{v}_{\text {mat }}^{t}\left(\boldsymbol{x}^{t+\Delta t}\right)=\boldsymbol{v}_{\text {mat }}^{t}\left(\boldsymbol{x}^{t}\right)-\left[\nabla \boldsymbol{v}_{\text {mat }}^{t}\left(\boldsymbol{x}^{t}\right)\right]\left(\boldsymbol{v}_{\text {mat }}^{t}\left(\boldsymbol{x}^{t}\right)-\boldsymbol{v}_{\text {msh }}\right) \Delta t
$$

Referring to fig. 2, it can be seen that (30) is nothing but a first order spatial development of the material velocity field in the upstream element associated with the nodal position $\boldsymbol{x}^{t}$.

\subsection{Lagrangian and Eulerian-Lagrangian zones}

Regarding now the global treatment of a casting, the idea consists in defining the solidified regions as Lagrangian (convected mesh) and the liquid or mushy ones as Eulerian-Lagrangian (regularized mesh under the constraint (26)). Therefore each node is affected to one of the two classes, according to the following rule, as illustrated in fig. 3.

$\checkmark$ Each node belonging at least to one solid-like element (i.e. a tetrahedron whose constitutive equation has been chosen elastic-viscoplastic, see section 2) is treated as Lagrangian (mesh velocity equals material velocity).

$\checkmark$ All other nodes, which then belong to liquid-like elements only, are treated as EulerianLagrangian (mesh velocity calculated independently of the material velocity).

This ALE formulation prevents the mesh from degenerating when fluid motion occurs in the casting, due to thermal convection. Also it allows the mesh boundary to follow the evolution of the free surface of the remaining liquid pool and then to model pipe formation.

\section{Application to an industrial case}

\section{$\underline{4.1 \text { Presentation of the studied casting }}$}


The parts studied here are elements of very large electro-magnets for the Institute for Nuclear Physics of the University of Mainz, Germany. Such magnets are used in an electron accelerator for fundamental nuclear research. They are cast by the foundry of Usinor Industeel and delivered fully equipped - coils excepted - to the university. Each magnet is composed of two identical parts, as illustrated in fig. 4. Four magnets - eight parts - should be manufactured.

These parts are very specific by their weight (125 tons each), their dimensions $(2.5 \times 7.0 \times 1.0$ $\mathrm{m})$ and the steel grade. Their particular magnetic properties require the use of a carbon-free steel, whose chemical composition, developed by the research centre of Usinor Industeel, is close to pure iron.

The manufacturing route includes several stages:

- Elaboration of steel at the steelwork of Le Creusot.

- Gravity casting in molds made of sand with a thermoset resin. Each casting needs two steel ladles.

- Trimming of the riser by blowtorching.

- Heat treatment to relax the residual stresses.

- Machining (a flatness tolerance of $0.1 \mathrm{~mm}$ throughout the $7 \mathrm{~m}$ long basis of the part is achieved).

Regarding the shape of the central pipe defect occurring in the riser, the results obtained with the numerical simulation have been compared with the real measurements carried out on the first two parts elaborated.

\subsection{Numerical modelling of solidification}

The dimension of pieces, the required quality level and short manufacturing times lead to the optimisation of the casting operation by numerical modelling. This has been carried out with THERCAST $^{\circledR}$ software. Preliminary computations have been done, only using the heat transfer module of the software. This has permitted a fast determination of the shape and the volume of the riser, as well as of the different elements of the mold. The geometry that has been finally determined, using a single central riser, is shown schematically in fig. 5.

In a second step, a full thermomechanical computation has been done in order to precisely determine the shape of the primary shrinkage defect in the riser. The steel material properties are given in table 1. Using symmetry conditions, only half of the casting has been calculated. As shown in fig. 6, the configuration includes seven subdomains: the cast part and six components of the mold. As the software permits non coincident meshes at interfaces between subdomains, each component has been meshed separately, without any interface constraint. The part has approximately 120000 tetrahedral elements and the mold subdomains 373000 . This corresponds to an average mesh size of $0.10 \mathrm{~m}$ in the part. In a first approach, the mold has been considered as non deformable. Only the deformations affecting the part have been calculated. The part cools down in the mold during approximately $127 \mathrm{~h}$. Then the mold is removed, which is associated in the 
simulation with a global change of the thermomechanical boundary conditions. The same heat transfer coefficient is then applied to the entire surface of the part, to model heat transfer with surrounding air by convection, except on the lower surface which is in unilateral contact with the basement of the mold. The heat exchange through this interface is defined by a higher heat exchange coefficient. The complete cooling of the part has been simulated, until a maximum temperature of about $50^{\circ} \mathrm{C}$ has been reached. The time step is automatically stabilized (Jaouen, 1998) to a value of $50 \mathrm{~s}$ attained after $2 \mathrm{~h}$ (process time). The process time being quite long (around $333 \mathrm{~h}$ ), the simulation requires a long computational time: 15 days on a IBM44-P270 machine.

\section{$\underline{4.3 \text { Comparison between measurements and computation. Discussion }}$}

In fig. 7, the shape of the pipe in the riser is shown for different process times: $2,8,16,24,32$ and $41 \mathrm{~h}$. As indicated by the distribution of the liquid fraction, which is plotted on the same figure, this last time is close to the time at which solidification is completed, which is around $36 \mathrm{~h}$. It can be seen that the last region to solidify is located at the bottom of the v-shape of the pipe shrinkage, which has almost reached its final shape at this time.

This series of pictures illustrates well the ALE formulation. The mesh follows the evolution of the free surface of the alloy because of the flux condition (26). In the other regions, the mesh is regularized, yielding an homogeneous mesh size throughout the computational domain. Twenty complete remeshings have been needed in order to avoid mesh degeneracy along the pipe surface. Such complete remeshings may affect other regions of the domain and this is the reason why the mesh is not exactly conserved in solidified regions.

The four first pictures of fig.7 show that when a liquid free surface is still present $\left(g_{s}=0\right)$, it remains perfectly horizontal. This is a consequence of the clear distinction between liquid-type and solid-type constitutive equations. A more approximate treatment of the liquid, obtained for instance by an empirical extrapolation of the parameters of an elastic-viscoplastic constitutive equation, would have lead to a curved free surface. Here, the use of a Newtonian flow rule for the liquid, using a sufficiently low viscosity (here taken equal to $1 \mathrm{~Pa} . \mathrm{s}$ ), results in this flat surface.

When the free surface is in a mushy state, it is no more horizontal. The rapid increase of the viscosity with the solid fraction explains that the alloy cannot be completely sheared under very low stresses. Then the mushy free surface, between the free surface of the solid shell and the free surface of the liquid pool, is not horizontal but curved. After complete solidification, the free surface is "frozen" and has reached its final shape. Only very small further changes in its shape are caused by thermal contraction effects.

The final shape of the pipe calculated by the simulation is given in fig. 8a. There is a reasonably good agreement with the profile experimentally measured on the two first real parts that have been cast when writing this paper (fig. 8b). The v-shape is globally well simulated. The predicted maximum depth is $1.48 \mathrm{~m}$, versus $1.43 \mathrm{~m}$ measured, which is excellent. However the precise shape of the pipe is not obtained. 
A first remark can be done regarding the top level in the riser. During the process, the maximum altitude of the solidified shell ( $z$ coordinate of point $A$ in fig. $8 \mathrm{a}$ ) decreases by $80 \mathrm{~mm}$ according to the computation. It can be seen from fig. $8 \mathrm{~b}$ that this displacement is highly underestimated by the calculation (by $180 \mathrm{~mm}$ ), the measured value being around $260 \mathrm{~mm}$. The modelling of contact cannot be responsible for it, since no friction has been accounted for along the isolating material of the riser $\left(\mu_{f}=0\right.$ in (14)). An alternative source of error could be an overestimated transient heat transfer between the alloy and the isolating material, inducing a faster "freezing" of the top periphery of the riser as compared to the real situation. Also one should not forget that the computation has been done starting from an homogeneous temperature field in the part and in the mold. This approximation - the impact of which is difficult to estimate a priori - can be overcome only by performing the modelling of the filling of the mold, which has not been done in the present case.

Regarding the shape of the pipe, it can be seen that the computation is able to capture different regimes of the growth of the defect, particularly the latest stage during which the remaining pool is in a mushy state of increasing consistency, which yields to a steeper wall. However, the analysis of the quantitative prediction would deserve a more detailed study, especially regarding the sensibility of the results to the mesh size, and to the material parameters: transition temperature between liquid and solid-type constitutive equations (in the present case $T_{C}$ corresponds to $g_{s}=0.75$ ), values of the rheological parameters.

It is interesting to plot the velocity field during solidification. In fig. 9, this is done in the longitudinal section of the part (time $10 \mathrm{mn}, 2,8,12,24$ and $28 \mathrm{~h}$ ). When the part is still completely liquid, the free surface level decreases uniformly due to the thermal contraction of the whole liquid contained in the mold. During the first $20 \mathrm{mn}$, the level change is $50 \mathrm{~mm}$. Then the solidification proceeds and during the rest of the process there is an additional decrease of $30 \mathrm{~mm}$ of the maximum altitude of the solidified shell in the riser, which yields the above mentioned $80 \mathrm{~mm}$ downwards displacement. In fig. 9, the velocity field illustrates the feeding flow issued from the riser. This flow is always found oriented towards the useful part of the casting. It is free from recirculations possibly created by natural convection. This might be surprising. However, one should not forget that this velocity field is the one of a single phase medium, although the alloy is in a mushy state, involving two different phases behaving differently. This point is very important and it is clear that a detailed analysis of the liquid feeding flow would necessitate an effective twophase formulation with a clear distinction between the liquid velocity field and the solid velocity field. As far as we know, such two-phase semi-solid models have been developed and tested only in isothermal conditions, see for instance (Nguyen et al., 1994; Lalli, 1985; Toyoshima and Takahashi, 1991; Bay et al., 1998). Extension to non isothermal conditions - including solidification, i.e. associated mass transfer from the liquid to the solid phase - has not been yet clearly formulated in the literature. The corresponding numerical resolution remains to be developed and would certainly provide a better modelling of liquid feeding through a deformable mushy zone. Therefore, in the framework of a thermomechanical analysis, aiming also at the prediction of stresses and strains in the solid regions, we have privileged a single phase approach of 
the mushy state. Using such an approximation, the role of the riser is perfectly illustrated, showing a continuous and stable feeding flow issued from the riser, the value of which being between 10 and $20 \mu \mathrm{m} \cdot \mathrm{s}^{-1}$.

\section{An example with a comparison between the proposed method and a heat transfer alone method}

The casting shown in fig. 10 is a five meter high steel casting for the manufacturing of the top ram of a power hammer. Its weight is about 110 tons and half of the geometry is computed because of symmetry. The mesh of the casting has about 250000 elements. Complete solidification is obtained after about 34 hours. The solidification process has been computed by the thermomechanical approach described in the present paper and by a heat transfer alone approach. In the second case, the volume of the pipe defect is estimated by the method of Roch et al described in the introduction, but applied here in three dimensions. It can be seen that the shapes of the free surface predicted by the two methods differ significantly. Although no experimental validation is available on this part, this tends to strengthen the authors' conviction that the thermomechanical approach is a powerful method for free surface prediction and pipe defect estimation.

\section{Conclusion}

To summarise, the direct thermomechanical computation of pipe defect, which has been presented and applied here, seems very promising. By comparison with other methods for pipe estimation, it is directly applicable to any casting and is indifferent to the number of risers. This method also has the advantage of taking into account the deformation of the whole part. In particular the volume of the air gaps between the part and the mold is not directly assigned to the motion of the free surface in the riser. This is not the case in the models which are based on heat transfer only, or in fluid flow models: in such models, the sum of local volume contraction is entirely assigned to pipe growth. Obviously this is not correct since the liberated volume between part and mold should not participate in the pipe volume. This effect can be seen only when using a thermomechanical approach.

In the future, following this first approach, we can list a certain number of suggestions in order to improve the precision of the prediction:

$\checkmark$ The sets of thermo-physical and rheological data could be determined with a higher precision. This could explain the difference in the shape of the pipe that is observed. In particular, the discontinuities in the slope of the v-shape that can be seen on experimental measurements can come from the solidification path and/or from the alloy constitutive equation at high temperature near the solidus.

$\checkmark$ The mesh refinement is certainly a key-factor in order to capture the shape evolution with an improved precision. It can be thought that an adaptive and dynamic remeshing procedure which would follow automatically the advance of the solidification front during the whole process would quantitatively improve the prediction. 
$\checkmark$ Other factors might be important, such as the calculation of the deformation of the mold components, as it has an influence on the deformation of the part and the size of the air gaps.

$\checkmark$ Finally, in the current thermomechanical model, the mushy state is modelled using a onephase approach, the alloy obeying a pure viscoplastic constitutive equation within the solidification interval. This could be improved by modelling the mushy alloy as a twophase continuum, with distinction between the motion of the liquid phase and of the solid phase. The development of such a two-phase model and its implementation in the simulation package THERCAST ${ }^{\circledR}$ would provide a comprehensive approach, capable of modelling concurrently all the main phenomena participating in pipe formation.

\section{Acknowledgement}

This work has been supported by the French Ministry of Industry, the French Technical Center of Casting Industries (CTIF) and the companies Arcelor-Irsid, Ascometal, Atlantic Industrie, Aubert et Duval, Erasteel, Industeel and PSA. 


\section{References}

Arnold, D.N., Brezzi, F. and Fortin M. (1984), “A stable finite element for Stokes equation”, Calcolo, Vol. 21, pp. 337-352.

Barkhudarov M., You H., Ortega J., Beech J., Chin S.B. and Kirkwood D.H. (1993), "Experimental validation and development of Flow-3D for casting problems", Proc. $6^{\text {th }}$ Int. Conf. on Modelling of Casting, Welding and Advanced Solidification Processes, The Minerals Metals and Materials Society, Warrendale, Pennsylvania, pp. 421-434.

Bay, F., Barlier, J., Chastel, Y., Bobadilla, M. and Lovato, G. (1998), "Numerical modelling of extrusion for a semi-solid alloy. Application to rheological parameters identification in $\mathrm{Sn}-\mathrm{Pb}$ alloys", Proc. $8^{\text {th }}$ Int. Conf. on Modelling of Casting, Welding and Advanced Solidification Processes, The Minerals Metals and Materials Society, Warrendale, Pennsylvania, pp. 941-948.

Bellet, M. (2001), "Implementation of surface tension with wall adhesion effects in a threedimensional finite element model for fluid flow", Comm. Num. Meth. Engng, Vol. 17, pp. 563-579.

Bellet, M., Decultieux, F., Ménaï, M., Bay, F., Levaillant, C., Chenot, J.L., Schmidt, P. and Svensson, I.L. (1996), "Thermomechanics of the cooling stage in casting processes : 3D finite element analysis and experimental validation", Metall. Mater. Trans. B, Vol. 27, pp. 81-100.

Bellet, M. and Jaouen, O. (1999), "Finite element approach of thermomechanics of solidification processes", Proc. Int. Conf. On Cutting Edge of Computer Simulation of Solidification and Casting, Osaka, I. Ohnaka and H. Yasuda (eds.), The Iron and Steel Institute of Japan, pp. 173-190.

Celentano, D., Oller, S. and Oñate, E. (1993), “A finite element model for thermomechanical analysis in casting processes”, Journal de Physique, Vol. 3, pp. 1171-1180.

Chenot, J.-L. and Bellet, M. (1995), "The ALE method for the numerical simulation of material forming processes", Proc. Numiform'95, 5th Int. Conf. on Numerical Methods in Industrial Forming Processes, Ithaca, S.-F. Shen and P.R. Dawson (eds.), Balkema, Rotterdam, pp. 39-48.

Cross, M. and Campbell, J. (eds.) (1995), Proc. 7th Int. Conf. on Modelling of Casting, Welding and Advanced Solidification Processes, London, The Minerals Metals and Materials Society, Warrendale, Pennsylvania.

Decultieux, F., Bellet, M., Le Floc'h, A., Delagnes, D. and Levaillant, C. (1997), "Development of stress during the solidification of an aluminium alloy: experimental and numerical assessment of influence of elasticity parameters during solidification", Proc. SP'97, 4th Int. Conf. on Solidification Processing, J. Beech and H. Jones (eds.), The University of Sheffield, pp. 195-197.

Ehlen, G., Schweizer, A., Ludwig, A. and Sahm, P.R. (2000), "Free surface model to predict the influence of shrinkage cavities on the solute redistribution in castings", Proc. 9th Int. Conf. on 
Modelling of Casting, Welding and Advanced Solidification Processes, P.R. Sahm, P.N. Hansen and J.G. Conley, Shaker verlag, Aachen, pp. 632-639.

Fjaer, H.G. and Mo, A. (1990), "Alspen: a mathematical model for thermal stresses in direct chill casting of aluminium billets", Metall. Mater. Trans. B, Vol. 21, pp. 1049-1061.

Fortin, M. and Fortin, A. (1985), "Experiments with several elements for viscous incompressible flows”, Int. J. Num. Meth. Fluids, Vol. 5, pp. 911-928.

Inoue, T. and Ju, D.Y. (1992), "Simulation of solidification and viscoplastic stresses during vertical semi-continuous direct chill casting of aluminium alloy", Int. J. Plasticity, Vol. 8, pp. 161183.

Jaouen, O. (1998), Modélisation tridimensionnelle par éléments finis pour l'analyse thermomécanique $d u$ refroidissement des pièces coulées (Three-dimensional finite element modelling for the thermomechanical analysis of the cooling of castings), $\mathrm{PhD}$ Thesis (in french), Ecole des Mines de Paris.

Lalli, L.A. (1985), "A model for deformation and segregation of solid-liquid mixtures", Metall. Mater. Trans. A, Vol. 16, pp. 1393-1403.

Ménaï, M. and Bellet, M. (1995), "Thermomechanical coupling during solidification: a 3D finite element approach", Proc. 7th Int. Conf. on Modelling of Casting, Welding and Advanced Solidification Processes, M. Cross and J. Campbell (eds.), The Minerals Metals and Materials Society, Warrendale, Pennsylvania, pp. 723-730.

Moitra, A., Thomas, B.G. and Storkman, W. (1992), "Thermomechanical model of steel shell behavior in the continuous casting mold", Proc. EPD Congress 1992, The Minerals, Metals and Materials Society, Warrendale, Pennsylvania, pp. 547-577.

Naterer, G.F. (1997), "Simultaneous pressure-velocity coupling in the two-phase zone for solidification shrinkage in an open cavity", Modelling Simul. Mater. Sci. Eng., Vol. 5, pp. 595-613.

Nguyen, T.G., Favier, D. and Suéry, M. (1994), "Theoretical and experimental study of the isothermal mechanical behaviour of alloys in the semi-solid state", Int. J. Plasticity, Vol. 10, pp. 663-693.

Niyama, E., Uchida, T., Morikawa, M. and Saito, S. (1982), "A method of shrinkage prediction and its application to steel casting practice", Cast Metals Research, Vol. 7, pp. 52-63.

Roch, F., Combeau, H., Chevrier, J.-C. and Lesoult, G. (1991), "Numerical model for prediction of the final composition and pipe formation of heavy steel ingots", Proc. 5th Int. Conf. on Modelling of Casting, Welding and Advanced Solidification Processes, M. Rappaz, M.R. Ozgü and K.W. Mahin (eds.), The Minerals Metals and Materials Society, Warrendale, Pennsylvania, pp. 789-795.

Smelser, R.E. and Richmond, O. (1988), "Constitutive model effects on stresses and deformations in a solidifying cylinder", Proc. 4th Conf. on Modelling of Casting and Welding 
Processes, A.F. Giamei and G.J. Abbaschian (eds.), The Minerals, Metals and Materials Society, Warrendale, Pennsylvania.

Thomas, B.G. and Beckermann, C. (eds.) (1998), Proc. 8th Int. Conf. on Modelling of Casting, Welding and Advanced Solidification Processes, San Diego, The Minerals Metals and Materials Society, Warrendale, Pennsylvania.

Toyoshima, S. and Takahashi, Y. (1991), “A numerical simulation of forming processes for semi-solid materials", ISIJ International, Vol. 31, pp. 577-582.

Vicente-Hernandez, P. (1994), Caractérisation rhéologique et microstructurale d'alliages métalliques à l'état semi-solide (Rheological and microstructural characterization of metallic alloys in the semi-solid state), PhD Thesis (in french), Ecole des Mines de Paris.

Weiner, J.H. and Boley, B.A. (1963), "Elasto-plastic thermal stresses in a solidifying body", J. Mech. Phys. Solids, Vol. 11, pp. 145-154.

Wiese, J.W. and Dantzig, J.A. (1990), "Modelling stress development during the solidification of grey iron castings", Metall. Mater. Trans. A, Vol. 21, pp. 489-497.

Zhang, J.Y., Usmani, A.S. and Lewis, R.W. (1994), "A realistic coupled thermomechanical finite element model of casting systems", Proc. 3rd World Conf. on Computational Mechanics (WCCM III), Chiba, Japan. 
viscoplastic strain rate sensitivity $m$ vs temperature $T\left({ }^{\circ} \mathrm{C}\right)$

$1600 \quad 1.0$

elastic-viscoplastic consistency $K(\mathrm{MPa})$ vs temperature $T\left({ }^{\circ} \mathrm{C}\right) \quad 20$ 700

elastic-viscoplastic strain rate sensitivity $m$ vs temperature $T\left({ }^{\circ} \mathrm{C}\right)$

$1488 \quad 20$

$20 \quad 0.08$

static yield stress $\sigma_{00}(\mathrm{MPa})$ vs temperature $T\left({ }^{\circ} \mathrm{C}\right)$

$1488 \quad 0.4$

$20 \quad 400$

$1400 \quad 0$

$1488 \quad 0$

Young modulus $E(\mathrm{MPa})$ vs temperature $T\left({ }^{\circ} \mathrm{C}\right)$

Poisson coefficient $v$

Table 1. Properties of steel used for the computation. For confidentiality reasons, actual values cannot be given. Typical values are given and the interpolation between the given values should not been assumed linear. 


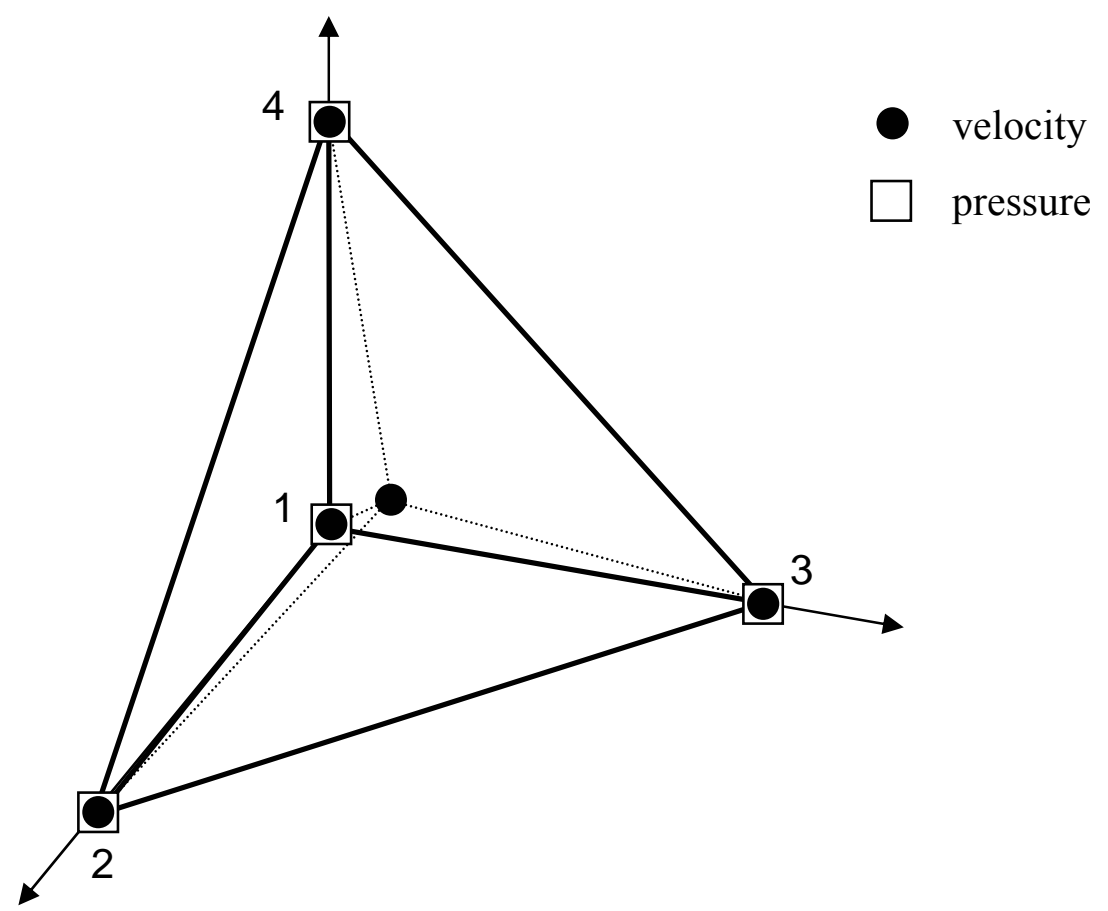

Fig. 1. P1+/P1 element. 


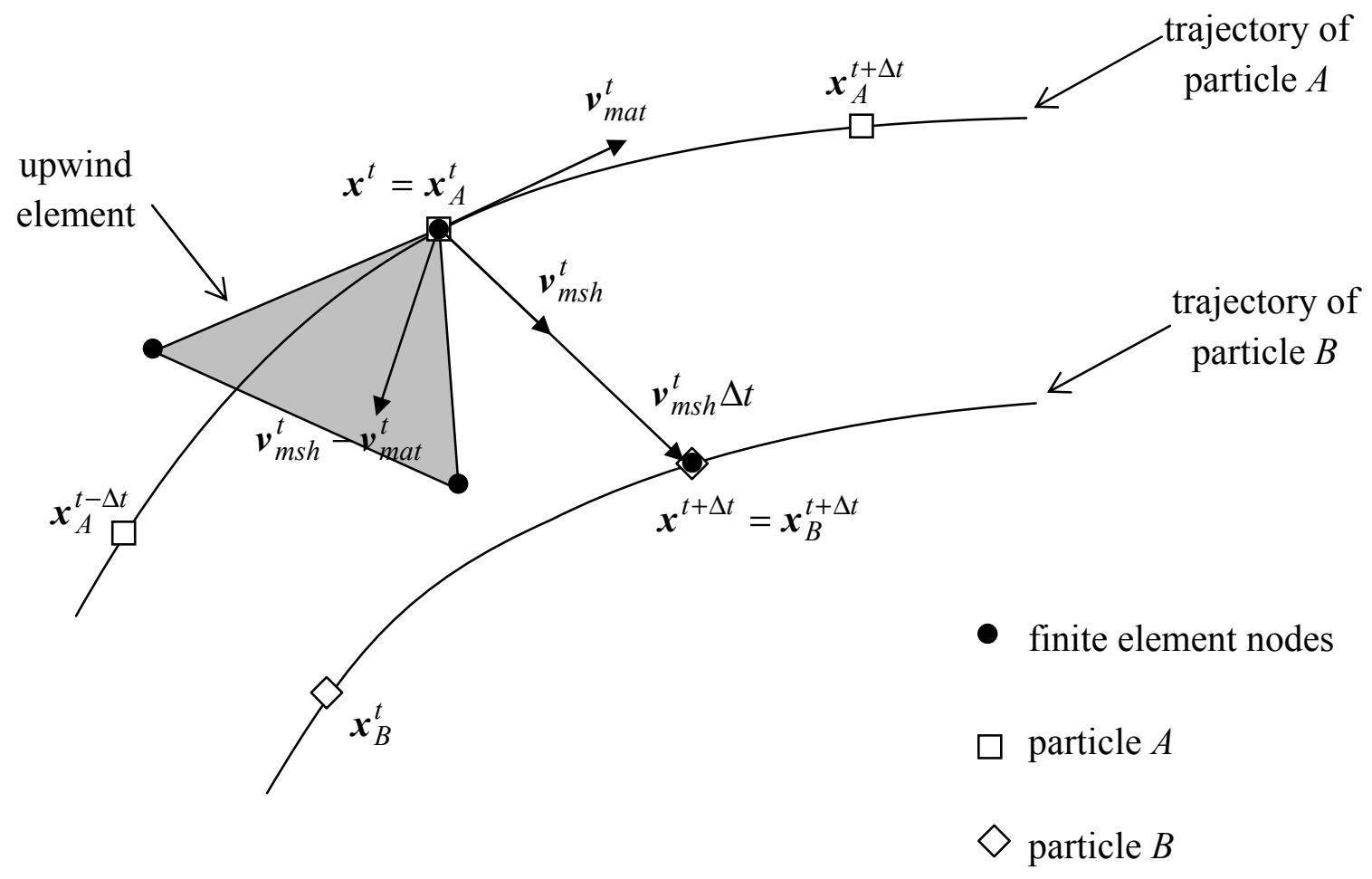

Fig. 2. ALE formulation: schematic in two dimensions. Updating of the location of a finite element node and subsequent identification of the upwind element. The materialization of the trajectory of two material particles $A$ and $B$ helps in the interpretation of equation (30). 


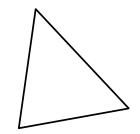

liquid-like element (purely viscoplastic, or Newtonian)

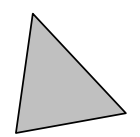

solid-like element (elastic-viscoplastic)

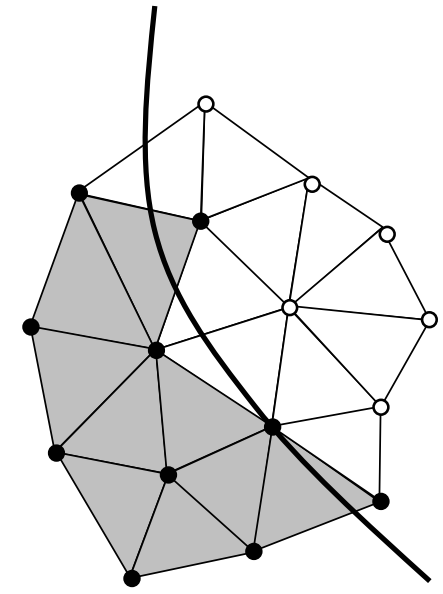

$\circ$

Eulerian-Lagrangian node

Lagrangian node

isotherm $T_{C}$

Fig. 3. Lagrangian and Eulerian-Lagrangian nodes, as determined by their belonging to solid-like and liquid-like finite elements. Schematic in two dimensions. 


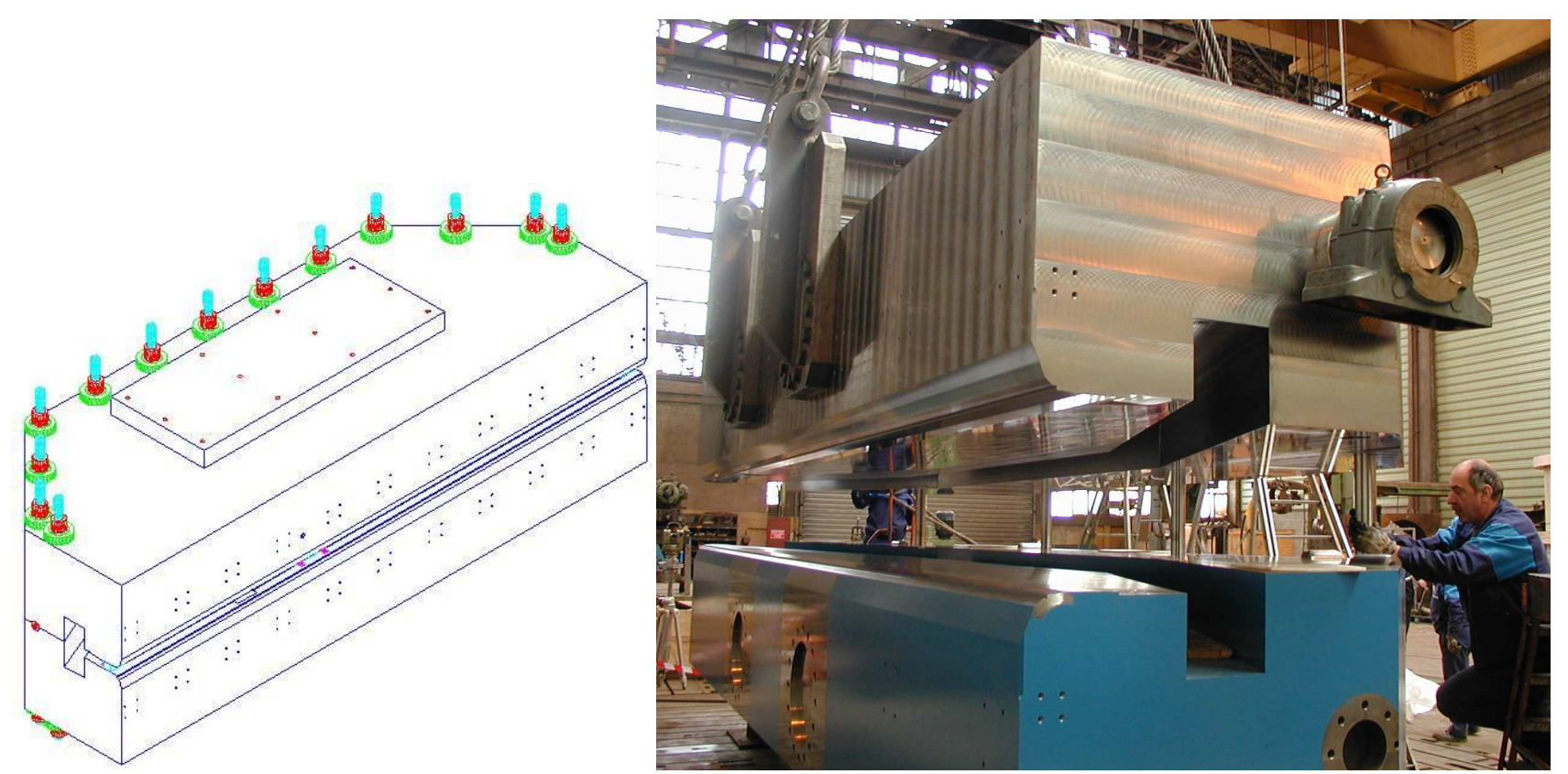

Fig. 4. On the left, schematic of the magnet, composed of two parts. On the right, magnet after machining of the two parts. 


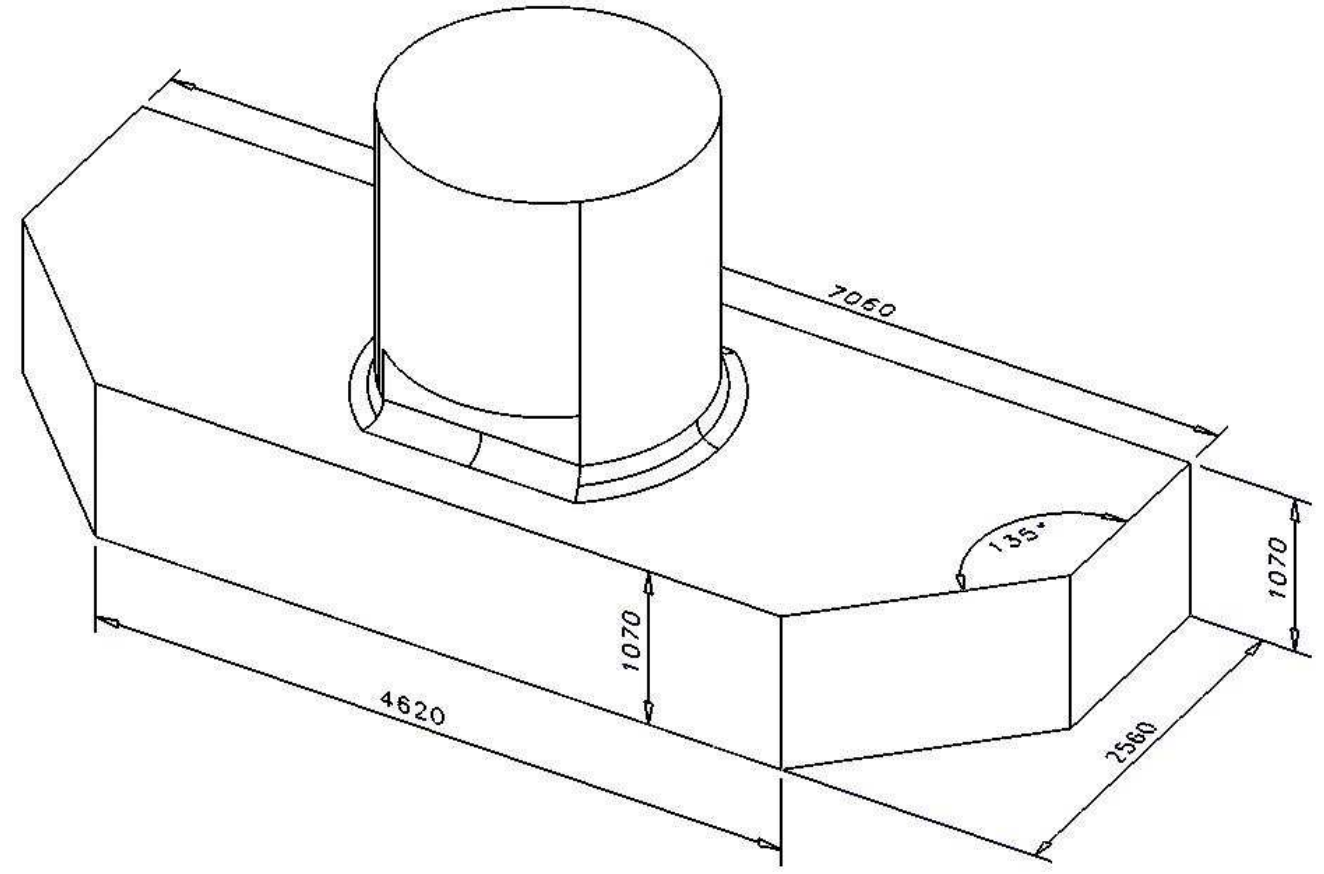

Fig. 5. Geometry of cast parts, including the central riser (dimensions in $\mathrm{mm}$ ). 


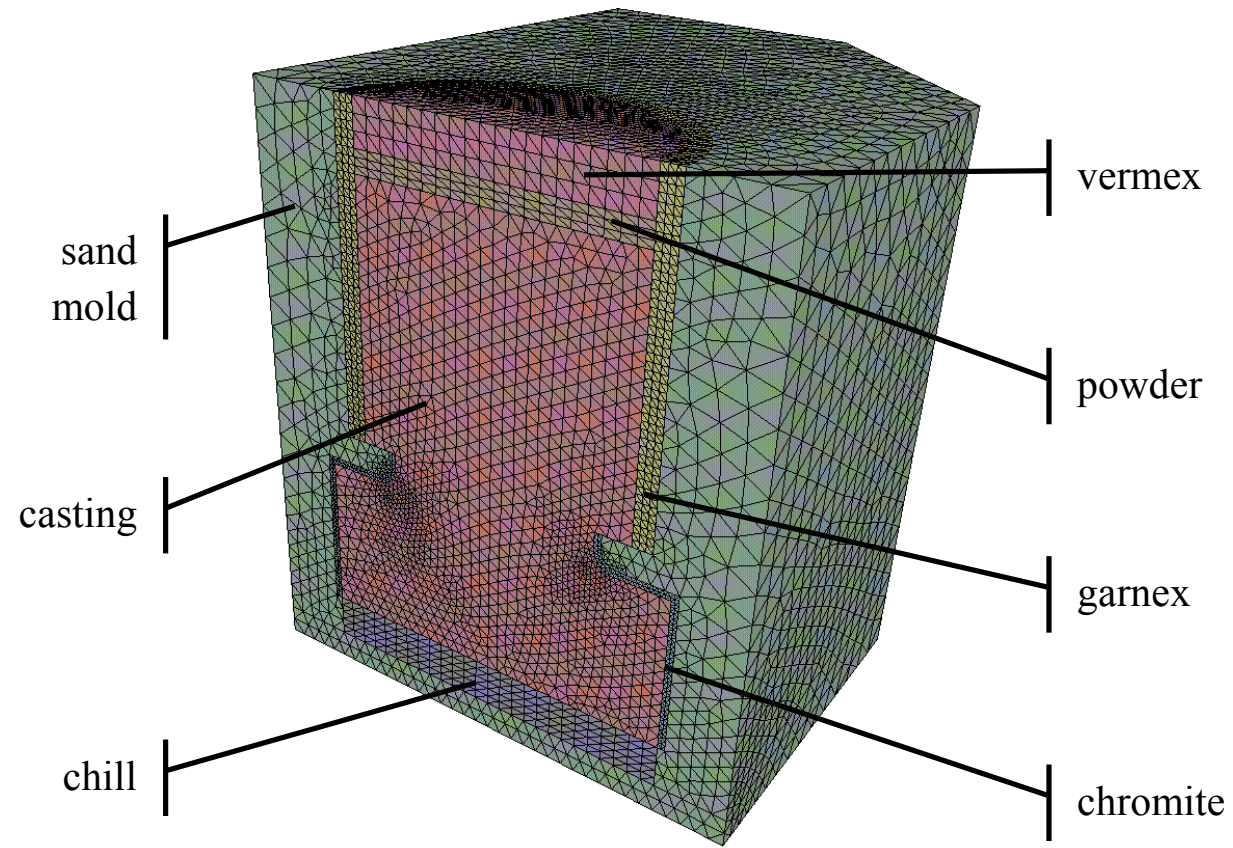

Fig. 6. Finite element mesh of the casting and the six different subdomains of the mould. 

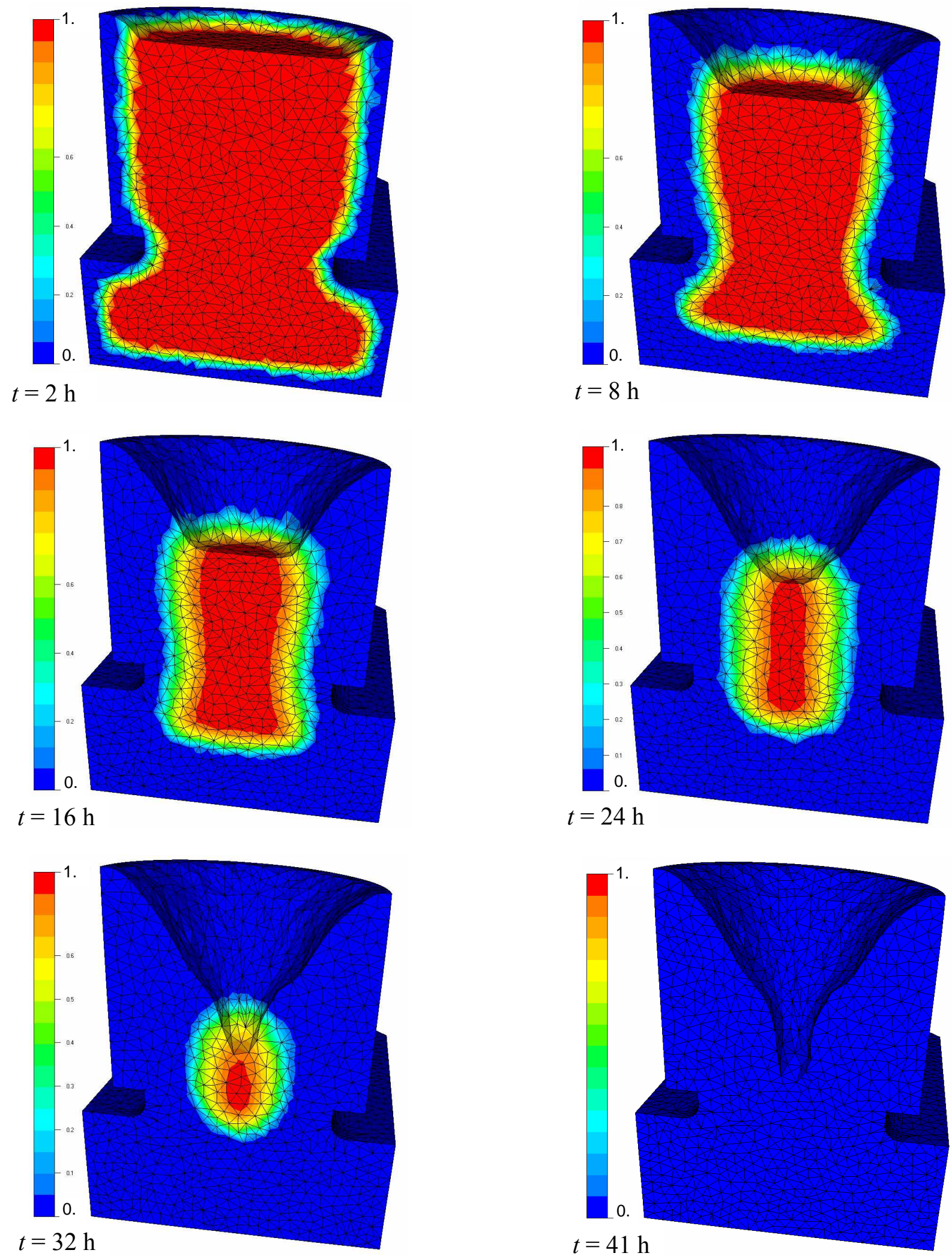

Fig. 7. Computation of the pipe formation. Iso-values of the liquid fraction. 


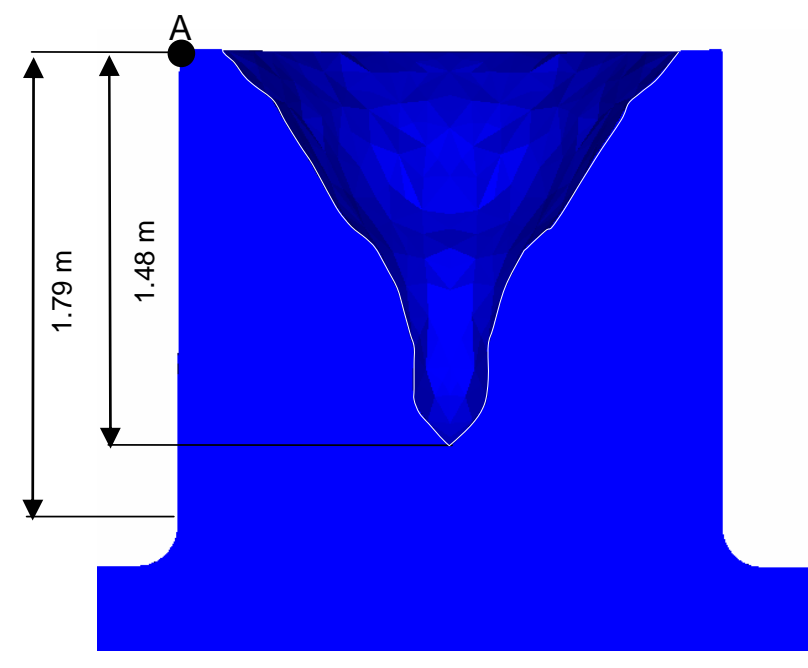

a) Calculated shape

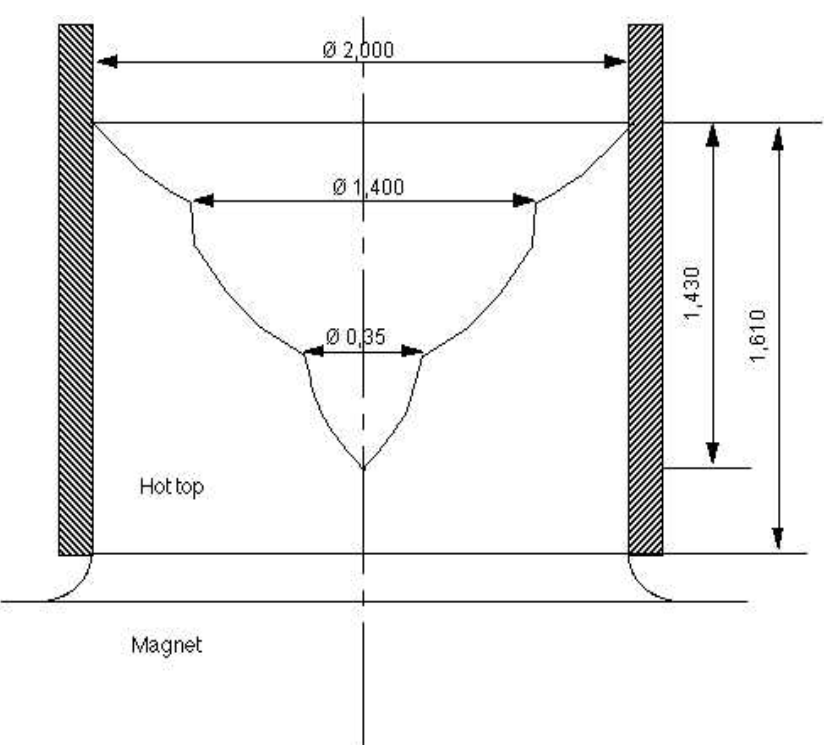

b) Measured shape

Fig. 8. Comparison of calculated (left) and measured (right) shapes of the pipe. The section plane is the longitudinal mid plane of the part. 


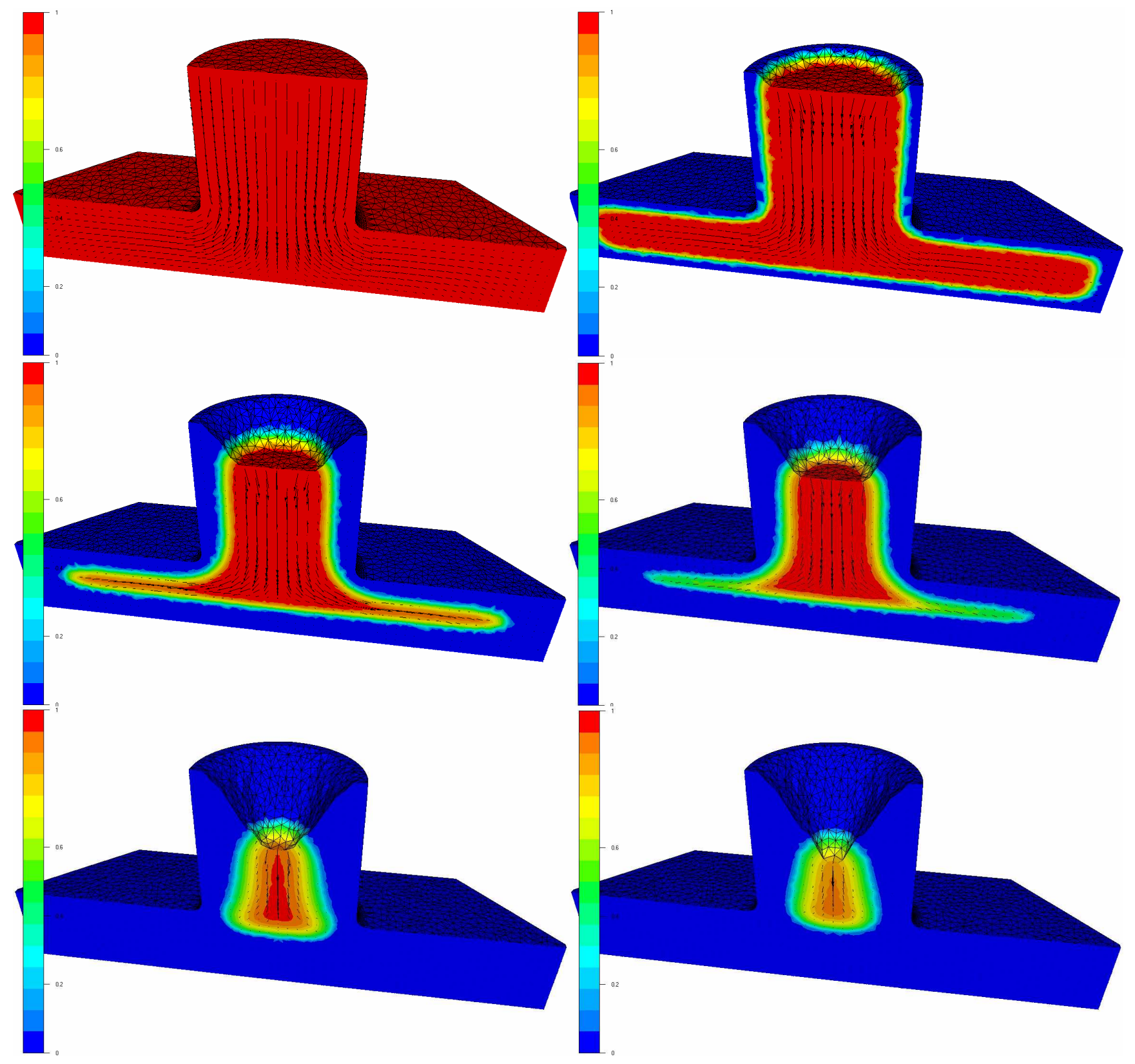

Fig. 9. Velocity field at different steps of the solidification process (10 mn, 2, 8, 12, 24 and $28 \mathrm{~h})$. Iso-values of the liquid fraction. 

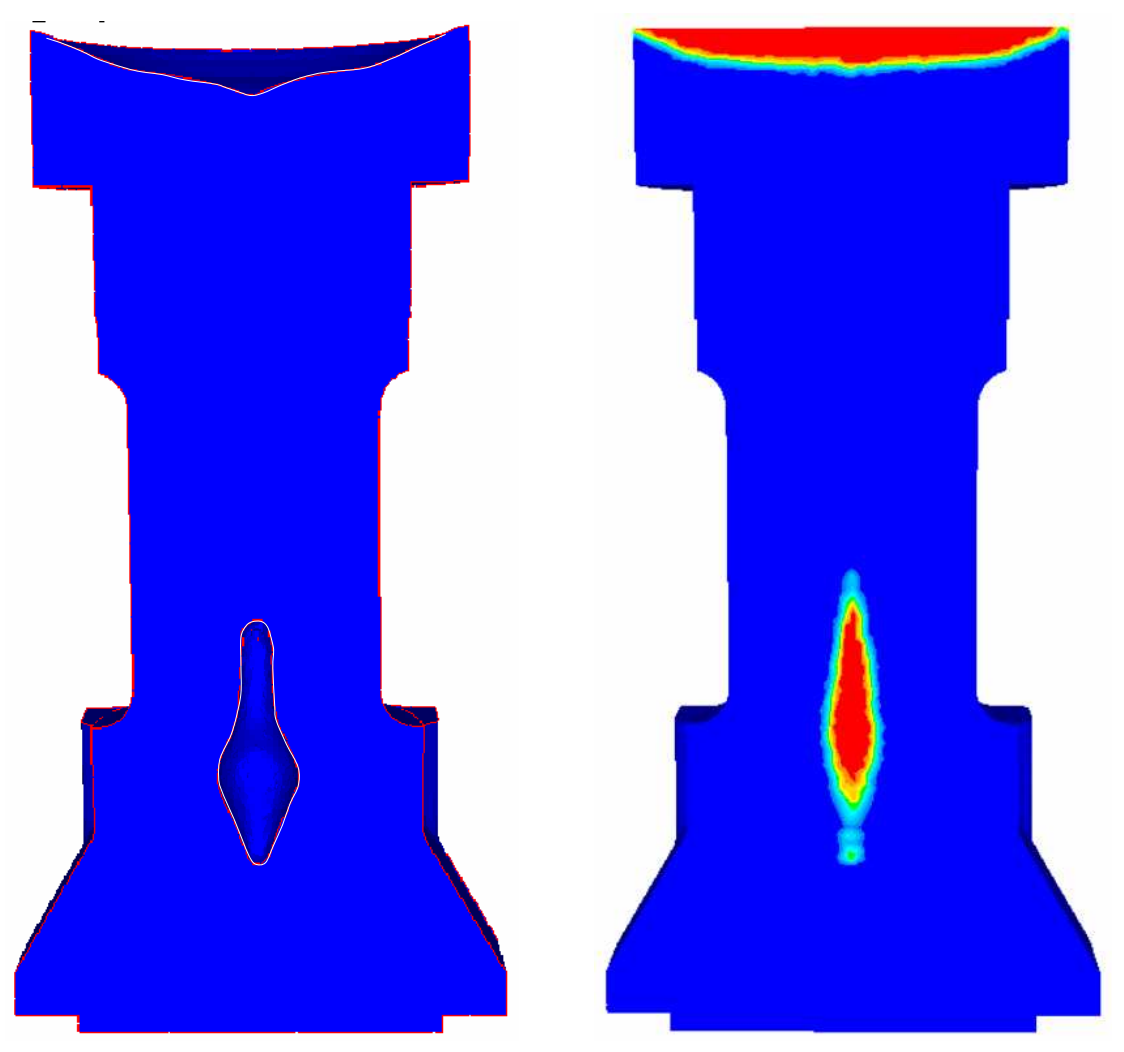

Fig. 10. Comparison of the shape of primary macroshrinkage obtained by the proposed thermomechanical method (on the left) and by the heat transfer alone method (on the right, the red - or light gray - zones corresponding to the location of the defect). The central macroporosity defect shown by both methods has been obtained by newly developed methods which will be described and discussed in future publications. 